\title{
Foreigner Talk in the ESL Classroom: Interactional Adjustments to Adult Students at Two Language Proficiency Levels
}

Marilyn Brulhart

\begin{abstract}
While native speakers plainly adjust their speech to accommodate non-native speakers on syntactic and prosodic levels, they are also making adjustments on the level of discourse. It has been argued that these interactional adjustments are the crucial ones to the promotion of language learning. The present study compared the proportion of nine interactional features used in the speech of four ESL teachers as they taught beginners and advanced level adult classes. As predicted, display questions and self-repeti-
\end{abstract}

\begin{abstract}
tions were used much less often with advanced students. The lack of other differences in interactional adjustments may be an artifact of the lesson content or teacher style. High variability in teacher behaviour was discovered. The marked reduction in use of display questions at the advanced level provided encouraging evidence that the ESL classroom is, in fact, preparing students for the real, communicative world. Implications for teacher training are pointed out.
\end{abstract}

Until recently, second language acquisition research has focused on the learner's production, and attempted to document the stages of development in the acquisition process. Some contemporary studies have shifted the focus to an examination of the learner's linguistic environment, that is, the target language available to the learner and how it affects the learning process.

It has been observed that native speakers (NSs) adjust their speech in conversation with non-native speakers (NNSs) in various ways. This modified register has been termed 'foreigner talk' (FT) by Charles Ferguson $(1971$, p.1), and defined as

A register of simplified speech . . . used by speakers of a language to outsiders who are felt to have very limited command of the language or no knowledge of it at all.

In the earlier studies, Ferguson and others investigated adjustments at the phonological, prosodic, lexical, and, mainly, syntactic levels of linguistic analysis. In comparison to speech between NSs, FT is characterized by

$*$ slower rate of delivery
$*$ increased loudness 
* clearer articulation

* exaggerated pronunciation

* more pauses

* more emphatic stress

* shorter utterances

* lower syntactic complexity

* more avoidance of low frequency items and idiomatic expressions

The focus of research shifted once again when Michael Long (1981a, p. 259) made an important distinction between input modifications to the linguistic forms used, and interactional modifications to the functions served by those forms, which occur at the level of discourse. Discourse modifications include such phenomena as increased numbers of self-repetitions and confirmation checks.

An example (Long 1983a) will serve to illustrate both what is meant by this distinction, and the fact that input and interaction modifications can occur independently.

(1) NS-NS speech

NS: When did you finish?

NS: Ten.

(2) Foreigner Talk-modification in form only

NS: What time you finish?

NNS: Ten o'clock.

(3) Foreigner Talk-modification in function only

NS: When did you finish?

NNS: Um?

NS: When did you finish?

NNS: Ten clock.

NS: Ten o'clock?

NNS: Yeah.

Exchanges like example (2) are often found in pidginized forms of English (for example, between migrant workers and their NS supervisors). The input modifications (uninverted WH-question, deletion of $d o$, and lack of verb inflection) allowed the NNS to understand and complete the exchange in only two turns. Example (3) is typical of conversations in studies between speakers of similar social status (for example, the NS and NNS university students in Freed 1981). The utterance form has not deviated from NS-NS norms, but the interactional structure of the conversation has. The NS has added a self-repetition and a confirmation check, resulting in a six-turn exchange to accomplish what the NS-NS exchange does in two. As is apparent from this example, examining interaction involves utterances in context, that is, takes into account the surrounding utterances of both speakers. For instance, the confirmation check in (3) can only be recognized in light of the NNS' preceding utterance. It should also be noted that interactional aspects of foreigner talk are all phenomena found in NS-NS 
speech. The greater frequency of use of these features in FT is what distinguishes it from NS-NS speech.

Presumably, this simplified register of speech provides comprehensible input to the learner at an appropriate level to allow for communicative interaction as well as language learning. But Long suggests it is the interactional rather than the input modifications which are essential to producing comprehensible input for the NNS (Long 1983b). Evidence in support of this claim is found in Long's comparison of the speech of NSs to NSs and NNSs in conversations generated by six different tasks (1981a). There were no significant differences in the two types of NS speech on 4 out of 5 measures of input modification. NSs did use significantly shorter utterances in addressing the NNSs, but measures of syntactic complexity, and lexical density and frequency were not significantly different in the two groups. However, frequencies on 10 out of 11 interactional measures were significantly different. NS speech to foreigners as compared to that of other NSs contained, for example, more expansions, self- and other-repetitions, comprehension checks, confirmation checks, and clarification requests.

The study reported here investigated these and three other interactional features of discourse in ESL classroom speech, by comparing the frequency of use of each feature with beginner and advanced level classes.

A quasi-experimental study was conducted in which naturalistic data were collected of four teachers' classroom speech as they carried out formal, teacher-centred instruction of adults at the beginner and advanced level of a community college ESL program.

Independent variables were:

1. Student English language proficiency (at two levels-beginner and advanced)

2. Teacher (at four 'levels' as represented by four teachers).

While other studies of foreigner talk have treated subjects as equally good representatives of a common NS behaviour construct, here that assumption was tested in the treatment of teacher as a separate variable. Each teacher was observed teaching one beginner level and one advanced level class, making a total of eight observations. Observing each teacher at both proficiency levels provided control of the teacher variable.

Dependent variables were:

\section{Or-Choice Questions}

These include a choice of two or more possible answers in the questioning move.

T: Did the rest of you read this article?

Or you heard it on the radio or on TV?

$$
* * * * *
$$


T: Do all the chores?

Do all the chores or help?

\section{Expansions}

The NS repeats all or part of their own or the NNS's preceding utterance, and includes grammatical function(s) not supplied previously.

T: Lady. She's a lady.

$$
* * * * *
$$

T: You came by bus?

$$
\text { S: By bus. }
$$

\section{Self-Repetitions}

These are partial or complete, exact or semantic repetitions of the NS's own utterance.

T: How do you say this word, $M$ ?

How do you say that word?

$$
* * * * *
$$

$\mathrm{T}$ : Does that look familiar to you?

The picture looks pretty familiar, doesn't it?

\section{Other-Repetitions}

The NS repeats the NNS's utterance in this instance.

T: And he is ?

S: Hungry.

T: Hungry.

T: Pardon me?

S: And Wall Street.

T: And Wall Street. OK.

\section{Display Questions}

These are questions for which the questioner already knows the answer.

T: How do you say this word, M.?

T: Can you give me

S: Back money.

$T$ : What do we call thatmoney back, money back? S: Return.

\section{Referential Questions}

These request unknown information or opinions in which the speaker is interested.

$\mathrm{T}$ : What did you read about?

$$
* * * * *
$$

T: Is that a democratic way?

$$
\text { ****** }
$$

T: What do you think?

\section{Comprehension Checks}

The NS attempts to determine whether their previous utterance has been understood. 
T: So past tense is, from yesterday, come-came, right?

$* * * * *$

T: OK? (rising intonation)

$* * * * *$

T: Do you understand 'leave'?

Do you know what that means?

\section{Confirmation Checks}

The NS requests confirmation that they have correctly understood the NNS.

T: Did they leave from Vancouver?

Is that what you said?

$$
* * * * *
$$

$\mathrm{S}: \mathrm{X}$ does it mean?

T: What does it mean?

(rising intonation)

\section{Clarification Requests}

The NS indicates that the NNS's utterance has not been understood and requests clarification.

S: From XX (Quebec)

$\mathrm{T}:$ From?

$$
* * * * *
$$

$$
\begin{aligned}
& \text { S: I like - um - XX } \\
& \text { steak }
\end{aligned}
$$

T: I'm sorry, what kind

of steak?

The subjects were one male and three female ESL teachers, each with at least 5 years experience.* There were no extremes in teaching style or method. The average class size was 16 . The students were all adults and all classes contained both males and females from a variety of first language backgrounds. Oriental backgrounds (Chinese, Japanese, Korean or Vietnamese) were predominant, however, with seven of eight classes having between $64 \%$ and $92 \%$ Oriental Ll speakers. The NNS's first language may significantly affect a conversational partner's FT, but the present study does not control for this factor, nor has this interesting question been addressed in the literature to date.

The researcher audiotaped all of the observations in as unobtrusive a manner as possible. None of the subjects knew the purpose of the study, but they were told that teacher-student interaction was under scrutiny. They were asked to carry out a regular lesson, but told that any group work or non-teacher-fronted activity would not be recorded.

Forty-five minutes of instruction per class (following warm-up conversation) were transcribed and coded to reflect instances of the nine

* To protect the teachers' anonymity, all will be referred to by teacher number (1-4) and "she." 
interactional features. Fixed two-factor analyses of variance were performed on the frequency counts to address nine research hypotheses. The hypotheses can be summarized as follows: the ESL teachers' speech to advanced students, as compared to beginner students, will contain significantly more referential questions and significantly fewer of all the other interactional features studied. Considered together, and in a broader framework, these hypotheses mean it was expected that teachers would approach a NS-NS teacher talk register as their students approached NS proficiency.

\section{RESULTS AND DISCUSSION}

The top portion of Table 1 contains the average number of instances of each of the nine interactional features across three subsamples for each teacher at each language proficiency level. Each 45-minute observation was divided into three subsamples of equal numbers of utterances to provide a measure of within-subject variability for the analyses of variance. It will be noted that there are relatively large numbers of selfrepetitions and display questions in the data, but few or-choice questions and clarification requests. The bottom portion of the table indicates the significance of differences from analyses of variance for the three sources of variation-proficiency level, teacher, and teacher by proficiency level interaction, whereby the confidence level was set at a stringent $\mathrm{p} \leq .01$ to counteract the relatively small number of teachers observed and any interdependence between the nine measures.

The main results were a significantly higher frequency of self-repetitions and display questions with beginner students than with advanced students and a significantly lower frequency of referential questions. The teachers did not behave consistently as a group. They used significantly different numbers of self-repetitions, referential questions, comprehension and confirmation checks. There was one significant (and two trends towards) interaction between proficiency level and teacher. Depending on which teacher is considered, referential questions were either increased substantially or not at all at the advanced level, constraining the generality of the main effect. It will also be noted that there were insufficient numbers of or-choice questions and clarification requests to permit conclusive tests, that the research hypotheses predicting fewer self-repetitions and display questions with advanced students were confirmed, and that all three significant proficiency level effects were in the direction predicted.

Discussions of the findings for each interactional feature follow, and are based on the figures in Table 1 . 
Table 1

Group Means and Sources of Variation from Analyses of Variance of Use of Nine Interactional Features of Discourse with Beginner and Advanced Students

\begin{tabular}{|c|c|c|c|c|c|c|c|c|c|c|c|c|c|c|c|c|c|c|c|}
\hline & & \multicolumn{2}{|c|}{$\begin{array}{l}\text { 1) } \\
\text { Or-choice } \\
\text { questions }\end{array}$} & \multicolumn{2}{|c|}{$\begin{array}{c}\text { 2) } \\
\text { Expansions }\end{array}$} & \multicolumn{2}{|c|}{$\begin{array}{c}\text { 3) } \\
\text { Self- } \\
\text { repetitions }\end{array}$} & \multicolumn{2}{|c|}{$\begin{array}{c}\text { 4) } \\
\text { Other- } \\
\text { repetitions }\end{array}$} & \multicolumn{2}{|c|}{$\begin{array}{c}\text { 5) } \\
\text { Display } \\
\text { Questions }\end{array}$} & \multicolumn{2}{|c|}{$\begin{array}{c}\text { 6) } \\
\text { Referential } \\
\text { Questions }\end{array}$} & \multicolumn{2}{|c|}{$\begin{array}{c}\text { 7) } \\
\text { Compre- } \\
\text { hension } \\
\text { Checks }\end{array}$} & \multicolumn{2}{|c|}{$\begin{array}{c}8) \\
\text { Confirm- } \\
\text { ation } \\
\text { Checks }\end{array}$} & \multicolumn{2}{|c|}{$\begin{array}{l}\text { 9) } \\
\text { Clarifi- } \\
\text { cation } \\
\text { Requests }\end{array}$} \\
\hline & & B & A & B & A & B & A & B & A & $\mathrm{B}^{-1}$ & A & B & A & B & A & B & A & B & A \\
\hline $\mathrm{T}$ & 1 & 0.7 & 1.0 & 7.0 & 6.0 & 23.3 & 13.7 & 16.7 & 17.7 & 36.0 & 12.3 & 3.0 & 23.7 & 16.0 & 8.7 & 7.3 & 6.0 & 3.7 & 0.7 \\
\hline A & 2 & 0.0 & 0.3 & 5.3 & 0.7 & 18.3 & 11.0 & 9.3 & 6.7 & 55.0 & 8.7 & 1.0 & 2.0 & 4.3 & 8.3 & 1.3 & 5.3 & 0.7 & 3.0 \\
\hline $\mathrm{H}$ & 3 & 0.3 & 0.7 & 2.7 & 7.7 & 36.7 & 24.3 & 28.3 & 15.3 & 63.7 & 12.7 & 3.7 & 45.3 & 3.3 & 2.7 & 8.0 & 15.3 & 0.7 & 2.7 \\
\hline $\mathrm{R}$ & 4 & 0.0 & 0.0 & 5.7 & 2.7 & 44.0 & 20.7 & 16.0 & 9.7 & 64.3 & 44.0 & 2.0 & 1.0 & 1.3 & 10.0 & 1.3 & 0.7 & 0.7 & 0.0 \\
\hline \multicolumn{2}{|c|}{$\begin{array}{c}\text { Proficiency } \\
\text { Level } \\
\text { Effect }\end{array}$} & \multicolumn{2}{|c|}{ n.s. } & \multicolumn{2}{|c|}{ n.s. } & \multicolumn{2}{|c|}{$.001 * *$} & \multicolumn{2}{|c|}{ n.s. } & \multicolumn{2}{|c|}{$.000 * *$} & \multicolumn{2}{|c|}{$.000 * *$} & \multicolumn{2}{|c|}{ n.s. } & \multicolumn{2}{|c|}{ n.s. } & \multicolumn{2}{|c|}{ n.s. } \\
\hline \multicolumn{2}{|c|}{$\begin{array}{l}\text { Teacher } \\
\text { Effect }\end{array}$} & \multicolumn{2}{|c|}{ n.s. } & \multicolumn{2}{|c|}{ n.s. } & \multicolumn{2}{|c|}{$.002 * *$} & \multicolumn{2}{|c|}{$.015^{*}$} & \multicolumn{2}{|c|}{$.014^{*}$} & \multicolumn{2}{|c|}{$.001^{* *} *$} & \multicolumn{2}{|c|}{$.006^{* * *}$} & \multicolumn{2}{|c|}{$.000^{* *}$} & \multicolumn{2}{|c|}{ n.s. } \\
\hline \multicolumn{2}{|c|}{$\begin{array}{c}\text { Interaction } \\
\text { Teacher } \\
\text { X Level }\end{array}$} & \multicolumn{2}{|c|}{ n.s. } & \multicolumn{2}{|c|}{$.016^{*}$} & \multicolumn{2}{|c|}{ n.s. } & \multicolumn{2}{|c|}{ n.s. } & n. & & & $2 * *$ & .01 & & & & & \\
\hline & & & & & & & EGEN & $*$ & & & $\begin{array}{l}\text { ginne } \\
\text { lvance } \\
=.01 \\
=.05\end{array}$ & $\begin{array}{l}\text { level } \\
\text { leve } \\
\text { end) }\end{array}$ & $\begin{array}{l}\text { lass } \\
\text { class }\end{array}$ & & & & & & \\
\hline
\end{tabular}




\section{Or-Choice Questions}

The scarcity of or-choice questions in the data, while preventing any statistical conclusions, is interesting in itself, since or-choice questions have been reported to be prevalent in FT outside classrooms (Hatch 1978, Long 1981b). The classroom context itself may limit their use. A teacher has not one but several conversational partners. With one partner, the meaning of a question which has not been understood must be negotiated or the topic dropped. An or-choice question supplies parts of possible answers which can be valuable clues to its meaning. In the classroom, on the other hand, a question which has not been understood by one student can often be directed unmodified to another until someone responds appropriately, providing the model for the rest of the class. Or-choice questions may then be useful or even necessary to sustain conversation outside but not in classrooms.

\section{Expansions}

The interaction trend between teacher and proficiency level can be viewed as a tendency for teachers to adjust significantly but in different directions. Three of the teachers decreased use of expansions with advanced students and one showed a marked increase. The discussion of possible explanations for this result (albeit a nonsignificant result) will serve to introduce a number of factors which may affect interactional features of discourse along with the one proposed by the studythe students' proficiency level.

Use of expansions may be influenced by lesson content. One useful distinction is whether the lesson has a content or a form focus. For instance, Teacher 3's beginner lesson dealt exclusively in questions like "What did you have for breakfast?", or "How did you get to school today?" This was a past tense drill, and the teacher was quite obviously interested only in whether the tense was produced properly, and not in the content of the answer. Teachers 1 and 2, on the other hand, both focused on the content of utterances at the beginner level. For instance, Teacher 2 asked "What are some questions you might want to ask about registering?" in order to, familiarize the students with the registration procedure. It may be, then, that focus on content rather than form promotes the use of expansions (although it should be noted that only correlations, not causal relations, are shown here).

These three beginner lessons also suggest that control of content corresponded to a lower incidence of expansions. Teacher 3, with the lowest number of expansions, controlled the lesson tightly in supplying all of the questions and maintaining the central role in the classroom action. The other two elicited questions from students as well, and set up role play situations in which they were observers. The advanced 
lessons bear this relationship out. Teachers 2 and 4 exercised a great deal of content control in their grammar lessons and used few expansions, while Teacher 3, who led an open-ended, problem-solving discussion in which the students provided direction as well as opinions and attitudes, used expansions extensively-as confirmation checks following an unexpected student response, and as self- and other-repetitions following a breakdown in the students' comprehension. For example,

T: So you mean she

S: Nurse.

should look for a

nursing job.

Teaching style could be another important determining factor in use of expansions. Teacher 4's beginner lesson seems to contradict the 'increased control $=$ decreased expansions' equation. This teacher used a relatively high number of expansions in a tightly content-controlled lesson. The explanation may lie in her tendency to be a repeater. Expansions can be seen as a form of repetition, and she was the highest user of self-repetitions at both levels. Any influence of lesson content may have been partially offset, in her case, by this tendency. It may be seen in the larger framework of interactional devices to avoid conversational breakdown (strategies) and those to repair breakdown after it has occurred (tactics) proposed by Long (1983a). She seemed to be avoiding conversational breakdown in her use of repetition, and in several other ways as well. She treated topics briefly, made them salient in the beginner class through use of pictures, and used more comprehension checks than any other teacher at the advanced level. The importance of avoiding conversational breakdown may have outweighed the influence of control of lesson content on her use of expansions, as well as on other interactional features.

Teacher 3 , on the other hand, tended to use tactics rather than strategies. She employed significantly more confirmation checks than the other three teachers. A cursory look at the data reveals that she used self-repetitions twice as often as tactics (to repair breakdowns) than as strategies (to avoid breakdowns) with advanced students and almost always as tactics with beginners, and expansions at least as often to repair as to avoid conversational breakdown. Moreover, she was the lowest user of the strategy of checking students' comprehension. It may be that this tendency to repair rather than avoid trouble was outweighed by the influence of the lesson type at the beginner level, where she used fewest expansions, but may have strengthened the influence of the lesson type at the advanced level, leading to highest use there.

In summary, it appears that personal style in conjunction with the influence of particular lesson types are at least two of the factors which determine frequency of use of expansions. 


\section{Self-Repetitions}

Use of self-repetitions showed significant effects of both proficiency level and teacher. The first result confirms one of the research hypotheses. Presumably self-repetitions assist L2 learners, as they do L1 learners, by securing and maintaining their attention, providing a second chance to process an utterance, and making the conversation last. But as students gain competence, they have less trouble attending to a conversation, and are better able to recover meaning, reducing the teacher's need for self-repetitions at the advanced level, as is borne out in this study.

In addressing the differences among the teachers, factors of lesson content are again applicable. In contrast to their effect on expansions, a focus on content rather than form and decreased control of content seem to lead to fewer self-repetitions (Teachers 1 and 2 are low users at the beginner level). For much of her beginner lesson, Teacher 4, the highest user, was teaching and reviewing vocabulary words, activities traditionally involving repetition.

\section{Other-Repetitions}

The trend towards a teacher effect resides in Teacher 3's greater use of other-repetitions at the beginner level. As with self-repetitions, a content focus and more control of content (Teacher 1 and 2's beginner lesson) explain the relatively low use of other-repetitions at the beginner level. At the advanced level, however, Teachers 3 and 1, who use more other-repetitions than the other two, provide little control over lesson content but encourage a good deal of student input. This apparent contradiction can be explained by recognizing two distinct uses of otherrepetitions. One is for pedagogical purposes, to emphasize a grammar point, for instance. This is likely the case in Teacher 3's beginner lesson. The other is to affirm a student's response, whether from the language or content point of view. In other words, a teacher might repeat a student's utterance to encourage and reward him: an exuberant tone, for instance, could carry the message that the comment is a good one and important enough to be repeated for the whole class. Teacher 3 and 1 's problem-solving advanced lessons probably elicit more other-repetitions because personal affirmation lies closer to hand when dealing with a student's own experience and opinions. Teaching style may also be a factor in the form of differing perceptions on the part of teachers as to the importance of affirmation of students' responses.

\section{Display Questions}

The use of display questions shows a clear proficiency level effect in 
the direction predicted. The lower frequency in their use at the advanced level is a pedagogically important finding. It has been noted that display questions do not in general invite learners to respond at length and even less to initiate new topics and thus sustain interaction (Gaies 1983). In other words, they do little to promote communicative use of language. Furthermore, we know from comparison of in and out of classroom FT (Long \& Sato 1983, Long 1983b) that, in sharp contrast to teachers' FT, NSs speaking to NNSs ouside classrooms employ very few display questions. If the goal of the language classroom is to prepare learners linguistically for the real, communicative world, then it would be comforting to know that ESL teaching is on the right track in cutting down on display questions as the students' proficiency increases. This result supports that contention, with the qualification that not all teachers replace the display questions with referential questions.

Lesson content once again seems to be an important factor in determining the frequency of an interactional feature. Display questions would seem useful for teaching vocabulary, which is often a large part of lower level lessons (e.g., Teacher 4's beginner lesson in this study). They are probably less useful for the teaching of discourse negotiation, presumably a larger part of higher level lessons.

Teacher 3's use of display questions was clearly affected by lesson content. She was the highest user at the beginner level, not surprising given that she conducted a question and answer drill. And she was among the low users at the advanced level with a problem-solving lesson (which abounded in referential questions). Display questions would seem less likely than referential questions to lead to conversational breakdown, which may explain why Teacher 4 , who has been shown to avoid breakdown, continued to use high numbers of them at the advanced level.

\section{Referential Questions}

There was a significant increase in referential questions with advanced students, as well as significant differences in teacher behaviour. However, the significant interaction effect (between proficiency level and teacher) constrains the generality of the proficiency level effect, and reflects the fact that certain teachers boost referential questions with advanced students, and others do not.

Insofar as teachers are not prone to using referential questions, there is some justification for extending Long's criticism of the beginner second language classroom to the advanced level based on these findings. It could, indeed, prove to be a place which, in general, "offers little opportunity to the learner to communicate in the target language or to hear it used for communicative purposes by others" (Long 1983b, p. 218). 


\section{Comprehension Checks}

The teachers used comprehension checks in significantly different ways. Aspects of lesson methodology probably played a part. For instance, Teacher 4 used visual aids so extensively in her beginner lesson that they may have obviated the need for comprehension checks. On the other hand, the complexity of Teacher 2's advanced lesson may have led her to use a relatively high number of them. Then, too, if the information flow is primarily from student to teacher, as in Teacher 3's advanced lesson, comprehension checks will be less frequent.

The notion of use of strategies or tactics as a personal style may help -explain the differences. Comprehension checks can be viewed as a strategy to avoid conversational breakdown. Teacher 3 , who has been described as one who repairs rather than avoids trouble, does, indeed, employ few comprehension checks at either level.

\section{Confirmation Checks}

Confirmation checks are used relatively seldom by these teachers. Long (1983b) and Early (in press) both report few confirmation checks in the ESL classroom. Early suggests the reason is that while confirmation checks are used as a tactic to repair conversational breakdown, teachers tend to avoid breakdown and so have less use for them than NSs outside the classroom. The exception proves the rule in that Teacher 3, who does not tend to avoid breakdowns, does, in fact, use the highest number of confirmation checks at both levels. The type of lesson and the direction of information flow also seem to influence numbers of confirmation checks.

\section{Clarification Requests}

There were too few clarification requests in the data to draw any conclusions. It may be that teachers maintain such tight control over their lessons that they can anticipate student responses, or at least hazard a guess with a confirmation check.

\section{CONCLUSION}

The present study adds to our knowledge of NS-NSS registers for the setting of the classroom, the roles of teacher and student, and the task of formal teacher-fronted discussion. It suggests that some interactional features are rarely used in the classroom (or-choice questions and clarification requests), some are not used to significantly different extents at the beginner and advanced proficiency levels (expansions, other-repetitions, comprehension and confirmation checks) and some are heavily 
used features which are employed with highly different frequencies with beginner and advanced students (self-repetitions, display questions, and, with qualification, referential questions).

It also suggests that high or low use of the interactional features studied is not associated with the English language proficiency level of the students alone. Other possible factors in the use of FT (or even triggers of FT, if a causal relationship can be shown) might be:

1. aspects of lesson content which affect such variables as amount of teacher control over content or direction of information flow, amount of emphasis on form versus meaning, and linguistic complexity of the material;

2. teaching style as affected by the tendency to use strategies to avoid or tactics to repair conversational breakdown.

It appears that FT is influenced by a combination of factors-personal style in conjunction with lesson content, methodology, student proficiency level, linguistic background of the students, and probably others as well.

A third major finding is the extent to which teachers can vary in their behaviour. The absolute frequencies of discourse features at a proficiency level differed in many cases, and the amount of adjustment was highly variable. Moreover, teachers modified in opposite directions on a few measures.

Long and Sato's conclusion that "NS-NSS conversation during SL instruction is a greatly distorted version of its equivalent in the real world" (Long \& Sato 1983, p. 284) is mitigated by the findings here, at least for SL instruction at the advanced level. While the ratio of display to referential questions at the lower level was 25 to 1 (and in Long and Sato's study only 4 to 1 ), it was on average 1 to 1 at the advanced level. It seems that the disparity in distribution of display and referential questions in and out of classrooms is not as pronounced for ESL teachers' speech to advanced students (although this result should be checked against NS speech to advanced NNSs outside the classroom).

More studies are called for to extend our knowledge of NS-NNS discourse for various contexts, tasks and addressees, to establish triggers of FT, and then to discover which discourse modifications, if any, actually facilitate second language acquisition.

There will be implications for teacher training. While it seems to be generally agreed that the learner's linguistic environment is an important aspect of the acquisition process, teachers are not on the whole aware of the linguistic adjustments they make with their foreign students, nor do teacher training curricula address input and interactional adjustments, and which types of lessons affect them. I would suggest that they 
should, on both counts. The extent of individual variability in discourse usage discovered in the present study suggests that some teachers may have the intuitive ability to fine tune their lesson activities to promote discourse patterns to suit the language learners' needs. Others of us may need to be taught how to do that optimally.

\section{REFERENCES}

Early, M. (in press). Linguistic input and interaction in the content classroom. In R.R. Day (Ed.), Talking to learn: conversation in second language acquisition. Rowley, Mass.: Newbury House.

Ferguson, C.A. (1971). Absence of copula and the notion of simplicity. In D. Hymes (Ed.), Pidginization and creolization of language. London: Cambridge University Press.

Freed, B. (1981). Foreigner talk, baby talk, native talk. International journal of the sociology of language, 28, 19-39.

Gaies, S.J. (1983). The investigation of language classroom processes. TESOL quarterly, $17(2), 205-217$.

Hatch, E.M. (1978). Discourse analysis and second language acquisition. In E.M. Hatch (Ed.), Second language acquisition. A book of readings. Rowley, Mass.: Newbury House.

Long, M.H. (1981a). Input, interaction and second-language acquisition. In H. Winitz (Ed.), Native language and foreign language acquisition. New York: Annals of the New York Academy of Sciences.

Long, M.H. (1981b). Questions in foreigner talk discourse. Language learning, $31(1), 135-157$.

Long, M.H. (1983a). Native speaker/non-native speaker conversation and the negotiation of comprehensible input. Applied linguistics, 4(2), 126-141.

Long, M.H. (1983b). Native speaker/non-native speaker conversation in the second language classroom. In M.A. Clarke \& J. Handscombe (Eds.), On TESOL '82. Pacific perspectives on second language learning and teaching. Washington, D.C.: TESOL.

Long, M.H. \& Sato, C.J. (1983). Classroom foreigner talk discourse: forms and functions of teachers' questions. In H.W. Seliger \& M.H. Long (Eds.), Classroom oriented research in second language acquisition. Rowley, Mass.: Newbury House.

\section{THE AUTHOR}

Marilyn Brulhart has an MA in ESL, and degrees in Applied Linguistics and Mathematics, from the University of British Columbia. She has done EFL/ESL with the Canadian International Development Agency's (CIDA) EAP for Business Management project in Wuhan, PRC, and in Vancouver, as well as with the Canada/Indonesia Language Project of the World University Services of Canada. Following the development of an advanced writing course for CIDA in Ottawa, she is working as an instructor in College Preparation English at Vancouver Community College. 